only one of the three cases with the deficiency developed anaemia in the course of the typhoid.

Psychosis is another recognized complication of typhoid which appeared in these cases, but it usually occurs in the acute febrile stage, and indeed may be the presenting symptom. The late onset of psychosis in typhoid is, however, well known to local psychiatrists (Singer, personal communication).

We wish to thank Dr. P. H. Teng, Director of Medical and Health Services, for permission to publish this paper. We gladly acknowledge our debt to Miss Lettie $\mathrm{Ho}$, health visitor, and $\mathrm{Mr}$. Tsui, head clerk, Sai Ying Pun Hospital.

\section{Fluctuating Hemiparesis in a Young Man}

British Medical fournal, 1969, 4, 280

Hemiparesis in early adult life is not common. A fluctuating hemiparesis is distinctly uncommon. The following case is therefore thought worth reporting.

\section{CASE Report}

The patient was a right-handed 26-year-old married man who worked as a chicken hatchery foreman. He and two sisters all had congenital nystagmus. In 1956 he became unconscious from a fall on the right parietal region. In 1961 he fell again, bruising his nose, and in 1964 he fell once more, injuring the right side of his face.

His present illness began on 29 June 1968 when his left foot began to slap as he walked, and within a few minutes the left leg became weak. Two days later weakness of the left arm was noted. There was no disturbance of consciousness, vision, or speech. In August he was admitted to hospital elsewhere. Examination at that time besides the congenital nystagmus revealed a left hemiparesis, pronounced in the lower limb with ankle clonus and extensor plantar response, but slight in the upper limb. There were signs of mild aortic incompetence, subsequently attributed to a bicuspid aortic valve. Blood count, erythrocyte sedimentation rate, and an electrocardiogram were normal, and eight blood cultures grew no pathogenic organisms. The possibility of subacute bacterial endocarditis was entertained and he received six weeks' treatment with oral ampicillin as an outpatient, Within a month the hemiparesis improved, ankle clonus could not be elicited, and the plantar response was flexor. Later, however, a fluctuating hemiparesis developed. The hemiparesis would worsen over one day and remain static for three weeks, during which time he had difficulty in eating and walking. Recovery occurred over a few days, and for three or four days he was able to walk almost normally. On two occasions during his illness he regarded himself as completely normal. During any one day he was better in the morning than in the evening.

From October headache occurred in the right parietal region a day or so before the worsening of the hemiparesis, then radiating to the right frontoparietal region. Since December six episodes of lightheadedness followed by clonic movements of the left arm and left leg for one to three minutes had occurred, associated on each occasion with pronounced hemiparesis. The patient's wife corroborated the story of fluctuating hemiparesis. A history of rhinorrhoea was not elicited.
C. R. FORREST, M.D., M.R.C.P.GLASG.

ThOMAS T. Y. LEE, M.B., B.S.

W. K. TSANG, M.B., B.S.

S. Y. YU, S.R.N.

Medical Department, Sai Ying Pun Hospital, Hong Kong.

\section{REFERENCES}

Chan, T. K., Todd, D., and Wong, C. C. (1964). British Medical fournal, 2,102

Forrest, C. R., Matthews, R. N., Robertson, M. J., and Hanley, W. P. (1967). British Medical fournal, 2, 472.

Hersko, C., and Vardy, P. A. (1967). British Medical fournal, 1, 214.

McFadzean, A. J. S., and Chan, T. K. (1969). To be published.

McFadzean, A. J. S., and Choa, G. H. (1953). British Medical fournal, 2,360
On admission to the Churchill Hospital in May 1969 he was not disorientated and had no obvious difficulty in spatial orientation. When walking he tended to drag his left foot, and had left hemiparesis, moderate in the lower limb and slight in the upper limb, but sparing the face, There was no sensory impairment. Uncorrected visual acuity was Jaeger 6 in each eye. The fundi were normal and there was pendular horizontal nystagmus. The blood pressure was 120/80. A grade 3/6 early diastolic murmur was heard at the left sternal edge on expiration. There was no evidence of cardiac failure.

Investigations.-Platelet count 152,000/cu. mm., cholesterol 182 mg./100 ml., Wassermann reaction negative, L.E, cells not found, serum electrophoresis normal. Pathogenic organisms were not grown on blood culture. $X$-ray examination of the skull showed a large osteoma of the right ethmoid sinus, eroding into the anterior cranial fossa through the region of the cribriform plate. The osteoma was irregular and from its edge air tracked into a large aerocele in the right frontal and parietal region. A right carotid arteriogram did not show evidence of a vascular malformation.

A diagnosis of aerocele of the right frontoparietal region complicating an osteoma of the right ethmoid sinus was made. At operation by Mr. J. Pennybacker on 22 May the right frontal aerocele was drained and the intracranial portion of the osteoma removed, the remainder (about two-thirds) being left for a later open ethmoid approach if this should prove necessary. Postoperatively he remained well, apart from two minor left focal fits of short duration. He was discharged from hospital on 31 May walking normally.

\section{COMMEnT}

Osteomas of the ethmoid sinuses are not uncommon. Intracerebral aerocele with hemiparesis has been described as a complication of an ethmoidal osteoma (Cushing, 1927), but a fluctuating hemiparesis from this cause appears to be unrecorded.

My thanks are due to Dr. J. M. K. Spalding and Mr. J. Pennybacker for permission to publish details of this case.

R. WRAY, M.B., CH.B.

Department of Neurology, The Radcliffe Infirmary, Oxford.

REFERENCE

Cushing, H. (1927). Surgery, Gynecology and Obstetrics, 44, 721. 